Philipp Berghofer*

\title{
Phenomenology and Experimental Psychology: On the Prospects and Limitations of Experimental Research for a Phenomenological Epistemology
}

https://doi.org/10.1515/jtph-2019-0006

Published online January 8, 2020

\begin{abstract}
Husserl's transcendental phenomenology is first and foremost a science of the structures of consciousness. Since it is intended to yield eidetic, i. e., a priori insights, it is often assumed that transcendental phenomenology and the natural sciences are totally detached from each other such that phenomenological investigations cannot possibly benefit from empirical evidence. The aim of this paper is to show that a beneficial relationship is possible. To be more precise, I will show how Husserl's a priori investigations on consciousness can be supplemented by research in experimental psychology in order to tackle fundamental questions in epistemology. Our result will be a phenomenological conception of experiential justification that is in accordance with and supported by empirical phenomena such as perceptual learning and the phenomenon of blindsight. Finally, I shall shed light on the systematic limits of empirical research.
\end{abstract}

Keywords: phenomenology, experimental psychology, epistemology, perceptual learning, blindsight.

\section{The a priori Character of Phenomenology and Its Relationship to the Empirical Sciences}

Husserlian phenomenology is an essentially a priori discipline. This is to say that phenomenological insights are neither justified by the senses or by introspection nor somehow inferred from what we sense or introspect. Instead, phenomenological insights are intuitive eidetic insights, insights of reason concerning structures of consciousness, particularly concerning structures of experiencing. For instance, with respect to visual perceptual experiences, we can gain insights such as:

\footnotetext{
*Corresponding author: Philipp Berghofer, Department of Philosophy, University of Graz, Heinrichstraße 26/5, Graz 8010, Austria, E-mail: philipp.berghofer@uni-graz.at. https://orcid.org/0000-0002-9044-0637
} 
I1 Perceptual consciousness is intentional, i. e., perceptual experiences are always directed at something beyond themselves.

I2 Perceptual experiences exhibit the phenomenal character of originary givenness, i. e., they present their objects in a distinctive way as "bodily present.”

I3 Perceptual consciousness is perspectival, i.e., perceptual experiences present their objects from a certain perspective.

I4 Perceptual consciousness is horizontally structured, i. e., immanent to perceptual experiences are anticipations of what the perceived object would look like from different angles and perspectives.

I5 Perceptual experiences are (a source of) evidence, namely inadequate evidence as opposed to adequate and apodictic evidence.

In our Husserlian framework, I1-I5 are a priori insights in structures of perceptual consciousness. They are necessarily true and are not the product of empirical evidence but can be immediately intuited. I5 already exemplifies that such phenomenological insights are of great epistemological significance. This will be further elaborated in the following section.

Husserl makes it clear that phenomenology is an a priori, eidetic science (cf. Hua III/1, p. 6) and that the source of phenomenological insights are immediate eidetic intuitions (cf. Hua III/1, pp. 157f.). Given the a priori character of Husserlian phenomenology, one might wonder if phenomenology is completely detached from the empirical sciences. In this section, I defend two claims.

(1) Phenomenology, as an eidetic science, is independent of the empirical sciences in the sense that eidetic intuitions are an independent source of immediate justification.

(2) Phenomenology and the empirical sciences are not completely detached from each other but can stand in a mutually beneficial relationship. Empirical evidence can undermine eidetic insights. Empirical evidence can support eidetic insights.

The idea defended in this paper is that empirical and a priori methods are distinctive methods that can occasionally be used for addressing the same questions. In this context, it might be helpful to formulate the counterpart of (1) from the perspective of the empirical sciences.

(1)^ The empirical sciences, being based on perceptual experiences, are independent of phenomenology in the sense that perceptual experiences are an independent source of immediate justification.

As a side note, there is still the difference that phenomenology can elucidate why perceptual experiences (and also eidetic intuitions) are a source of immediate 
justification, while such fundamental questions are beyond the scope of the individual sciences. However, these reflections on phenomenology as the ultimate science go beyond the scope of the present paper. Our focus is on (2). Particularly, how could phenomenology benefit from empirical evidence? Does Husserl allow for such a mutually beneficial relationship? While there are many passages in Husserl's oeuvre that imply that phenomenology due to its a priori character could not possibly benefit from empirical investigations (cf. particularly Ideas I, §8), there are insightful Husserlian reflections that suggest otherwise.

Perhaps the first issue that must be addressed concerns the (in-)fallibility of $a$ priori insights. Obviously, if a priori insights are considered infallible, there is no possibility of an empirical correction and no need for an empirical examination or validation of phenomenological investigations. The passage that is most often discussed in this context is Husserl's remark that

The possibility of deception is inherent in the evidence of experience and does not annul either its fundamental character or its effect [...] Even an ostensibly apodictic evidence can become disclosed as deception and, in that event, presupposes a similar evidence by which it is 'shattered'. (Husserl 1969, p. 156)

For the sake of accuracy, it should be mentioned that this passage allows for two readings. According to the first one, apodictic evidence is fallible. This is the reading I advocate. According to the second reading, only infallible evidence can really be apodictic, while those evidences that happen to be false can only be ostensibly apodictic. Hence, this second reading implies the infallibility of (really) apodictic evidence. I prefer the first reading as I believe that evidence must be interpreted phenomenologically. Different types of evidences denote how their contents/objects are presented to us. Accordingly, an evidence that $p$ is apodictic if it presents $p$ as apodictic, i. e., if $p$ is experienced as being absolutely indubitable. ${ }^{1}$

However, there is a more enlightening text in Husserl's oeuvre that is less often addressed. This is a text drafted by Edith Stein on behalf of Husserl. Here Stein and Husserl complain that the "independence of phenomenology" from empirical knowledge "has always been viewed as a claim to infallibility, to the impossibility of error."2 Stein/Husserl point out that "this, however, has never been claimed, and it also does not follow from the emphasis on the independent legitimacy and the

1 Such an interpretation is in accordance with Drummond (2007, pp. 37f.) and Soffer (1991, pp. 132f.). For an extensive and highly valuable discussion of this passage (cf. Heffernan 2009). Enlightening remarks concerning the fallibility of a priori insights can be found in BonJour 1998, $\S \S 4.4,4.5$. For a detailed analysis of Husserl's conception of apodictic evidence and how it relates to current debates (cf. Berghofer 2018a, 2019a).

2 It should be mentioned that, for all we know, Husserl was pleased with Stein's draft (cf. SobrakSeaton 2018, pp. 299f.). You find an English translation of this draft in Stein and Husserl (2018). 
peculiarity of eidetic cognition” (Hua XXV, p. 246). Quoting Theodor Elsenhans, they pose the following question: "When empirical science corrects what is phenomenologically intuited, should he [the phenomenologist] ignore this correction?" (Hua XXV, p. 248). Stein/Husserl respond:

Following the previous remarks, the answer to this cannot be doubtful: Experience [in the sense of empirical evidence] can call the attention of the investigator of essences [Wesensforscher] to the fact that there must be a mistake in his findings, it can prompt him to probe these findings in a new intuition and to correct them, but it itself cannot be a correction: Only by eidetic intuition can I gain eidetic insights. (Hua XXV, p. 248; my translation)

This is a highly interesting passage that not only reveals that eidetic intuition is fallible but also illuminates that empirical evidence can defeat, or at least cast doubt upon, justification gained by eidetic intuitions. In this light, we may subscribe to the following plausible claims that are distinctive for moderate forms of rationalism:

M1 Eidetic insights are fallible.

M2 Eidetic insights can be undermined by empirical evidence.

Accordingly, phenomenology is not totally detached from the empirical sciences. This is because eidetic intuitions are fallible and can be undermined/supported by empirical evidence.

This is some textual evidence that Husserl considers a priori phenomenological insights to be fallible and allows for a mutually beneficial relationship between phenomenology and the empirical sciences. Note that we also have good systematic reasons to subscribe to this claim. Logic and mathematics are the prime examples of $a$ priori disciplines but there is no doubt that logicians and mathematicians occasionally err in their a priori reasoning. Similarly, phenomenological insights are often contested and it seems presumptuous to insist on the infallibility of phenomenological reasoning.

However, so far, we have only established that the possibility of empirical evidence supporting phenomenological insights cannot be ruled out. What we want to do is to provide examples of empirical evidence supporting phenomenological insights. This will be done in Sections 3-5. Our focus will be on phenomenologicalepistemological principles concerning experiential justification. In the next section, I shall shed light on these phenomenological-epistemological principles.

\section{Some Phenomenological-Epistemological Principles}

While it is well established that experimental psychology can have a positive impact on philosophy of mind, I argue that this is also true for epistemology, particularly 
for some of Husserl's phenomenological-epistemological principles. What would be an example for a Husserlian phenomenological-epistemological principle? Considering Husserl's terminology, one principle suggests itself:

No conceivable theory can make us err with respect to the principle of all principles: that every originary presentive intuition is a legitimizing source of cognition, that everything originarily (so to speak, in its 'personal' actuality) offered to us in 'intuition' is to be accepted simply as what it is presented as being, but also only within the limits in which it is presented there. (Husserl 1982, p. 44)

The gist of this principle is the following claim:

PPA: Every originary presentive intuition ${ }^{3}$ is a source of immediate justification. ${ }^{4}$

Accordingly, originary presentive intuitions play a central role in Husserl's epistemology. But what does it mean for an intuition to be "originary presentive"? The term "originary presentive" is used by Husserl to denote the presentational character of certain intuitions that is typical of but not limited to perceptual experiences (cf. Erhard 2014, p. 175). Here we are talking about a distinctive form of givenness or way of an act presenting its objects/contents. This is not an external factor but an "inner, purely descriptive, or phenomenological character of perception" (Hua XIX/1, p. 358).

What unites different types of experiences such as perceptual experiences and a priori intuitions is their originary presentive character. What distinguishes them from mental states such as mere beliefs but also imaginative experiences is that the latter two lack this character of originary givenness.

Plainly the connection between the wider and narrower, the supersensuous (i.e. raised above sense, or categorial) and sensuous concept of perception, is no external or contingent matter, but one rooted in the whole business on hand. It falls within the great class of acts whose peculiarity it is that in them something appears as 'actual', as 'self-given'. Plainly this appearance [my emphasis] of actuality and self-givenness (which may very well be delusive) is throughout characterized by its difference from essentially related acts through which alone it achieves full clarity - its difference from an imaginative 'making present', or from a merely significative 'thinking of', which both exclude 'presence' (so to say appearance 'in person'), though not excluding the belief in being. [...] In the widest sense even universal states of affairs can be said to be perceived ('seen', 'beheld with evidence'). (Husserl 2001, p. 281)

$3 \mathrm{I}$ is to be noted that Husserl uses "intuition" in a broad sense including, e. g., perceptual experiences, introspective intuitions, and eidetic intuitions.

4 For detailed discussions of Husserl's principle of all principles (cf. Hopp 2016a and Berghofer 2018b). 
What sensuous and supersensuous intuitions have in common is that they present their objects in their actuality; they possess the phenomenal character of originary givenness. Husserl explicitly states that it is their appearance of actuality and selfgivenness that distinguishes them from mere signitive acts. Here, Husserl leaves no doubt that experiences must be classified phenomenologically and that nothing in the nature or essence of sensory and a priori intuition guarantees truth. Accordingly, when we say that an experience has the phenomenal character of originary givenness, we use the term "phenomenal character" in the way it is used in current debates. "By an experience's phenomenology I understand its phenomenal character, i. e., 'what it is like subjectively to undergo the experience"” (Tye 2015).

Phenomenologists are sometimes hesitant to employ this terminology of an experience's "phenomenal character." This might be because this term is often associated with "qualia," narrowly construed as mere sensations or sense data.

Unfortunately, philosophers and scientists almost always refer to qualitative phenomena with the generic term 'qualia' borrowed from British empiricism. But in empiricism the term 'qualia' denoted sense data, that is, entities greatly simplified with respect to the complexity of perceptual patterns qualitatively understood. (Albertazzi 2013b, p. 12)

Walter Hopp uses the term "phenomenological character," arguing that this term might be "slightly more neutral and potentially more encompassing than the more usual 'phenomenal character"' (Hopp 2016b, p. 44). Above, we have seen that in this context Husserl talks about the "inner, purely descriptive, or phenomenological character of perception" (Hua XIX/1, p. 358). However, I will stick to the term "phenomenal character." It should be clear that what I mean by this term is how an experience presents its object to the subject that undergoes this experience.

So far, we have seen that according to Husserl originary presentive experiences/intuitions are a source of immediate justification and we have clarified what Husserl means by saying that certain experiences have an originary presentive character. One focus of this paper is on the question of why experiences are a source of immediate justification. What gives them their justificatory force? According to my reading, Husserl provides a genuinely phenomenological answer to this question: Originary presentive intuitions justify by virtue of their distinctive phenomenal character. In particular, there are two key passages that suggest such a reading. In Ideas I Husserl says:

Immediate 'seeing', not merely sensuous, experiential seeing, but seeing in the universal sense as an originally presentive consciousness of any kind whatever, is the ultimate legitimizing source of all rational assertions. This source has its legitimizing function only because, and to the extent that, it is an originally presentive source. (Husserl 1982, p. 36) 
In his lectures on logic and epistemology from 1906/07, he says with respect to perceptual justification:

\begin{abstract}
A statement is grounded in experience, more precisely in perception and memory. It carries, so to speak, empirical weight. The clearer and more distinct the fulfilling empirical consciousness of givenness is, the more weight it carries. Obviously, we are not in a realm of contingent psychological subjectivity here either. Perception justifies by its phenomenological content, by its essence. Every singular perception with the same essence would justify 'the same' statement proper to it in a precisely similar way, no matter where and for whom. (Hua XXIV, p. 347) $)^{5}$
\end{abstract}

These passages suggest what I call a phenomenological conception of experiential justification. ${ }^{6}$ This is the claim that certain experiences gain their justificatory force from their distinctive phenomenology. More precisely,

PCEJ: Certain experiences have a distinctive, justification-conferring phenomenology, and if an experience $\mathrm{E}$ has such a justification-conferring phenomenology with respect to proposition $p$, E, by virtue of its phenomenology, provides immediate prima facie justification for believing that $p$.

PCEJ implies a close connection between epistemology and philosophy of mind. That such a close connection would be in Husserl's interest can be seen when he discusses the relationship between psychology and phenomenology (cf., e.g., Hua IX, particularly Hua IX 30, pp. 41f.). Not all contemporary phenomenologists would agree that phenomenologists should care about epistemology or that there is a distinctive phenomenological way of doing epistemology. Husserl, however, has been quite clear on this matter: "No epistemology without phenomenology" (Hua XXIV, p. 217).

My thesis is that PCEJ can be supported by results of experimental psychology. Here, I put emphasis on three examples: The work of Vittorio Benussi, the phenomenon of blindsight, and perceptual learning. We begin with the historical but systematically significant case of Vittorio Benussi.

5 This translation differs in one important respect from the translation offered by Hill. Hill translates Husserl's claim that "[d]er Grund wiegt um so schwerer, je klarer und deutlicher das erfüllende empirische Gegebenheitsbewußtsein ist" as "[t]he more weight the grounds carry, the clearer and more distinct the fulfilling empirical consciousness of givenness is." I have reversed the order to highlight Husserl's message that the degree of clearness and distinctness of the empirical consciousness determines the experience's justificatory force (the clearer and more distinct, the more force it has).

6 For a detailed discussion of passages suggesting such a reading of Husserl, cf. Berghofer 2018b. For a more general discussion of how Husserl's theory of evidence and his epistemology suggest such a reading, cf. Berghofer 2019a, 2019b. For an analysis of how such a Husserlian epistemology can enrich current debates, cf. Berghofer 2018c. 


\section{Exemplifying the Relevance of Experimental Psychology 1: Vittorio Benussi}

In current debates, it is often argued that perceptual experiences are a source of justification but are not in need of justification themselves.

Similarly, therefore, shouldn't we say that a perceptual experience can only justify a perceptual belief if the experience, itself, is justified? But the latter condition makes no sense. It does not make sense-it is a category error-to say that an experience is justified or unjustified. [...] You may be justified or unjustified in accepting a belief, but you cannot be justified or unjustified in having experiences; you simply have them. (Huemer 2001, p. 97; cf. also Ghijsen 2016, pp. 37f.)

This is also precisely Husserl's position: "Perception is nothing that can be justified, but it is itself justifying” (Hua XXIV, p. 8). However, in order for perceptual experiences to play this fundamental epistemic role, they must be distinct from beliefs. Beliefs are in need of justification, perceptual experiences are not. Perceptual experiences immediately justify, beliefs do not.

This is also reflected in Husserl's descriptive analysis of the relationship between perception and judgment. Husserl clearly distinguishes between perception and (perceptual) judgment (Hua XIX/2, p. 556) as well as between perceptual sense and perceptual statement or judgment-sense (Hua XX/1, p. 71). The perceptual judgment (Wahrnehmungsurteil) is based on the perceptual experience. The perceptual statement (Wahrnehmungsaussage) expresses "what is given in perception” (Hua XX/1, p. 70). Thus, perceptual sense and perceptual judgment are intrinsically connected. ${ }^{7}$ However, for Husserl, it is clear that perception cannot be identified with judgment since the same perceptual experience can be expressed by many different perceptual judgments and in most cases the perceptual sense clearly goes beyond the judgment-sense (Hua XIX/2, p. 550). The perceptual sense or content is, so to speak, richer than the judgment. ${ }^{8}$

However, does Husserl allow that perceptual experiences have the character of originary givenness but do not involve belief? In this context, Husserl's account

7 Husserl says that "in perceptual judgments the perception is in an inner relation to the signifying [Bedeuten] of the statement such that the sense of latter 'lies' somehow in the perception" (Hua $\mathrm{XX} / 1, \mathrm{p} .70)$.

8 I neither want to suggest that experiences are conceptual nor that Husserl thinks so. What I insist on, however, is that certain experiences immediately justify beliefs and that they do not just justify any belief but only those whose propositional contents are so to say in agreement with the experience's content. For Husserlian approaches towards contents of experiences and the question of conceptualism cf., e. g., Hopp 2011 and Madary 2017, ch. 4. 
of illusion and hallucination is of significance. "Misperception, hallucination, illusion: Purely descriptively speaking, they are real perceptions" (Hua XXXVIII, p. 10). This means that from the first-person perspective, there is no difference in undergoing these types of experiences. They have the same phenomenal character. Elsewhere, Husserl stresses that not only veridical perceptions but also hallucinations and illusions exhibit the character of originary givenness (cf. Hua XVI, p. 15). In this sense, hallucinations and illusions count as perceptual experiences. This is important because when discussing what he calls "unmasked hallucination," i. e., hallucinatory experiences which we know to be deceiving and not veridical, Husserl says, "in the unmasked hallucination: The object stands itself there, but we do not believe in its being. The further character, the character of self-appearance, is still there, but we do not believe, perhaps we doubt" (Hua XXXVIII, p. 11). ${ }^{9}$ Accordingly, having a perceptual experience representing $p$ does not imply believing that $p$, which shows most clearly that experiences are distinct from beliefs, which in turn allows experiences to be sources of immediate justification. However, this claim that perception is distinct from belief or judgment is far from uncontroversial.

Meinong, for instance, insists that "all perceptions [...] are judgments of existence [Existenzurteile]" (Meinong 1906, p. 388). It is part of the essence of perception to be a judgment of existence such that the content of the judgment corresponds to the content of the act of perception (Meinong 1888, p. 118). When you perceive a table in front of you, this act of perception involves the judgment "There is a table." This doctrine that perception essentially involves judging frequently occurs in central passages in Meinong's works and also plays an important role for Brentano (cf. Antonelli 2018, p. 154).

This is an example where it would be beneficial to have independent empirical data on the relationship between perception and belief. As we shall see, based on his experimental studies, Vittorio Benussi, a pupil of Meinong, concluded that the Brentano-Meinong thesis that perception essentially involves judgment is mistaken. Benussi was the experimental psychologist of Meinong's Graz school of object theory and experimental psychology. Benussi's modus operandi is distinguished by its "theoretical minimalism" (cf. Antonelli 1994, p. 87) and shaped by the intention "to replace the evidence of thought with the evidence of facts" (Fondo Benussi Carteggio, 9, autobiografia scientifica, archivio storico della psicologia italiana (University of Milan), cited in Antonelli 1994, p. 14). Benussi has been called "the most productive and effective experimental psychologist that Austria

9 What Husserl calls "unmasked hallucination" goes in current debates under the label of "known illusions" (Tucker 2013, p. 4). The purpose of these examples is exactly the same: To show that perceptual experiences are distinct from beliefs. 
had had" (Boring 1929, p. 439), and his experimental skills have even been compared to Leonardo's (Antonelli 1994, p. 28).

However, from the facts that Benussi was first and foremost an experimental psychologist and that he kept philosophical assumptions to a minimum when conducting his experiments, we should not conclude that he had no interest in philosophy, or that he did not draw philosophical conclusions from his experimental work. In his Autobiografia scientifica, Benussi states that "even in the most detailed investigations, despite all experimental labyrinths, the broadest purely theoretical-philosophical problems have been kept in sight" (Fondo Benussi Carteggio, 9, autobiografia scientifica, archivio storico della psicologia italiana (University of Milan), cited in Antonelli 1994, p. 3).

While it is true that Benussi's focus is clearly on the experimental work and not on discussing philosophical implications of his experiments, this shows that Benussi was interested in philosophical problems and that his experimental work cannot be detached from philosophical issues. In this context, we shall see that there is no doubt that Benussi has been aware that some of the theoretical-philosophical conclusions he draws from his experiments are diametrically opposed to central teachings of Meinong but bring him remarkably close to Husserl's phenomenology.

We shall see that Benussi's research in experimental psychology can be used to support the following two epistemologically significant theses:

B1 Perception is distinct from judgment/belief.

B2 Perceptual experiences have a presentive character.

Most of Benussi's work at his time in Graz focused on optical illusions. In his dissertation, he experimentally studied the Zöllner illusion and three years later he published an article entitled "Zur Psychologie des Gestalterfassens (Die MüllerLyersche Figur)”. This article was published in 1904 in Meinong's famous collected volume Untersuchungen zur Gegenstandstheorie und Psychologie. Zum zehnjährigen Bestande des Psychologischen Laboratoriums der Universität Graz which received considerable international attention. Here and in many of his later works, Benussi argues that the received view on optical illusions is fundamentally mistaken. The German term for optical illusions is "optische Täuschungen.” A “Täuschung” is a delusion. However, Benussi insisted that illusions such as the Müller-Lyer illusion are not delusions at all. A delusion is an error and an error can only occur with respect to a judgment (Benussi 1904, p. 391). An optical illusion, according to Benussi, should not be viewed as an error of judgment, which is why optical "delusions" are no delusions. Benussi prefers the term "inadequate representation” (Benussi 1904, p. 391; cf. also Benussi 1906).

The point is that Benussi's detailed studies on how people react to optical illusions and how such effects can be increased and reduced led him to the 
conclusion that the essence or nature of perception does not involve judgment (cf. Benussi 1904, p. 391). Twenty years later, he complemented his analysis of perception by arguing that the nature of perception is best disclosed by the term "presence." "To perceive an object means to experience its presence."10 Perception, by its very nature, has the character of "presence." Most importantly, perceptual experiences have this character of presence even if the intended object does not exist, "is 'physically' absent” (Antonelli and Manotta 2009, p. 149). ${ }^{11}$ This means that the character of perception is determined phenomenologically. Perception has the character of presence because, in contrast to other types of experiences such as believing, hoping, imagining, etc., in perception it seems to you that the object of your experience is present to you. "[T] he object is immediately [unmittelbar] and vividly [anschaulich] 'there,' 'in front of us”” (Antonelli 1994, p. 163). To put it differently, from the first-person perspective perception distinguishes itself by making its object present to you. This means that perception has a distinctive phenomenal character, namely, according to Benussi, the character of presence.

This, of course, demonstrates again that Benussi's experimental investigations have brought him considerably close to Husserl's phenomenology. As we have seen in the previous section, for Husserl, perceptions are originary presentive intuitions, which means that they present their objects as "bodily present" (Hua XVI, p. 14) and give them in a "fleshed out" manner (Hua XIX/1, p. 458). Furthermore, Husserl, just like Benussi, points out that not only veridical perceptions have the character of originary givenness (Husserl) or presence (Benussi) but also hallucinations and illusions. It is to be noted that Benussi is aware of the fact that his understanding of perception differs from Meinong's ${ }^{12}$ and moreover that it has a remarkable affinity to Husserl (cf. Antonelli 2018, p. 157). ${ }^{13}$

Interestingly enough, one of the main arguments in current debates for why perceptual experiences cannot be reduced to beliefs is motivated by the MüllerLyer illusion.

For instance, when someone who is familiar with the Müller-Lyer illusion is looking at the Müller-Lyer lines, he will have the perceptual experience that the lines are unequal, but he will not believe that the lines are unequal. This provides some reason to think that perceptual experiences are distinct from beliefs. (Ghijsen 2016, p. 37)

10 "Percepire un oggetto è viverne la presenza" (In La suggestione e l'ipnosi come mezzi di analisi psichica reale, cited in Antonelli 1994, p. 56, fn 59. Cf. also Antonelli 1994, p. 163).

11 With respect to "known illusions" such as the Müller-Lyer illusion, this means "that the character of presence does not change even if the observer knows that" her perceptual experience is illusionary (Antonelli 1994, p. 163).

12 Cf. an unpublished note of Benussi quoted in Antonelli (1994, pp. 57f).

13 Cf. a note of Benussi translated into German in Antonelli (1994, p. 58). 
For philosophers who hold that perceptual experiences are a source of immediate justification, it is central to point out that they are distinct from beliefs, and the Müller-Lyer illusion is considered the prime example for demonstrating this fact. Importantly, philosophers usually do not conduct experiments to back up this claim with experimental data. Nor do they refer to experimental studies. We may thus say that Benussi's investigations can provide experimental support for such claims.

\section{Exemplifying the Relevance of Experimental Psychology 2: The Phenomenon of Blindsight}

It is a distinctive implication of a phenomenological epistemology that epistemological investigations must be preceded or complemented by phenomenological analyses. For determining the epistemic force of, for instance, beliefs, imaginings, and perceptual experiences, you first need to clarify how these different types of mental states differ phenomenologically. The more precise your phenomenological analysis of, for instance, perception, the more accurate your conception of perceptual justification can become. This can be exemplified by discussing a philosophically significant real-world example that has recently gained much attention in neuropsychology: the phenomenon of blindsight. We speak of blindsight if a person due to a damaged visual cortex suffers from conscious blindness but is nevertheless able to correctly respond to visual stimuli that the person is not consciously aware of. Often, the conscious blindness is restricted to a region of the person's visual field, the person's blind field. Experimental research shows that in certain scenarios a blindsight patient would report that she does not see anything that is going on in her blind field but when forced to guess, she correctly identifies the stimulus.

After a lesion to the primary visual area, these patients report a lack of perceptual consciousness in the affected region of the visual field. However, when forced to guess the identity or presence of certain stimuli, they can perform well above chance level, sometimes to an impressive range of $80-90 \%$ correct. (Lau 2008, p. 249)

Lawrence Weiskrantz who discovered and thoroughly investigated the phenomenon of blindsight defines blindsight as "visual capacity in the absence of acknowledged awareness" (Weiskrantz 1998, p. x). Weiskrantz reports the following experimental result:

For example, even though D.B. could not see one's outstretched hand, he seemed to be able to reach for it accurately. We put movable markers on the wall to the left of his fixation, and again he seemed to be able to point to them, although he said he did not actually see them. Similarly, when a stick was held up in his blind field either in a horizontal or vertical position, 
and he was asked to guess which of these two orientations it assumed, he seemed to have no difficulty at all, although again he said he could not actually see the stick. After one such long series of 'guesses', when he made virtually no errors, he was told how well he had done. In the interview that followed, and which was recorded, D.B. expressed considerable surprise. (Weiskrantz 1998, p. 24)

Obviously, such experimental research has important implications for the nature of visual consciousness and philosophy of mind. However, it has also significant epistemological implications. For instance, the phenomenon of blindsight puts pressure on reliabilist conceptions of perceptual justification (cf. Ghijsen 2016, Smithies 2014, and Tucker 2010). To see why, consider the following hypothetical but empirically motivated example:

\begin{abstract}
A blindsighted person S looks at a piece of sheet, where there is a circle in the region where $S$ has normal sight (region R1) and a triangle at S's blind field (region R2). Based on her perceptual experience, $\mathrm{S}$ judges that there is a circle in R1 and a triangle in R2. Are both judgments equally justified? Even if we stipulate that the perceptual experience pushes $\mathrm{S}$ to believe that there is a triangle at R2, there is an important phenomenological difference that corresponds to an epistemological difference.
\end{abstract}

In this example, $S$ 's perceptual experience has a presentive character (phenomenal character of originary givenness) with respect to the circle. $S$ seems to be visually aware of the circle; the circle is presented to her within experience. This, however, is not true for the triangle. The triangle is only co-given to $S$ in the sense that $S$ expects there to be a triangle. She has the anticipation that by moving her head, she will become aware of a triangle. The triangle is in the horizon of her perceptual experience but it is not presented to her. This phenomenological difference fits perfectly with the epistemological difference. S's perceptual experience provides her with immediate justification for believing that there is a circle in R1. She sees that there is a circle, thus she is immediately justified in believing that there is one. Intuitively, however, S's perceptual experience does not provide her with immediate justification that there is a triangle in R2. Of course, if S knows that her blindsight faculties are reliable in the sense that in the past most of her blindsight seemings have turned out to be veridical, then $S$ may be inferentially justified in believing that there is a triangle. Based on her blindsight seeming and based on her knowledge that her blindsight seemings are reliable, she can justifiably believe that there is a triangle. But such justification cannot be immediate. A plausible conception of perceptual justification should be able to avoid the consequence that blindsight seemings can be an immediate source of justification (cf. Ghijsen 2016, pp. 17-19 and Smithies 2014, pp. 103f.).

If we agree that in this scenario S's experience justifies her in believing that there is a circle in R1 but does not justify her in believing that there is a triangle in 
R2, we see that this puts pressure on a number of conceptions of experiential justification that enjoy more or less popularity in current debates.

Reliabilism: Your experience E representing that $p$ immediately justifies you in believing that $p$ iff $\mathrm{E}$ is the product of a reliable process.

Truth-Externalism: Your experience $\mathrm{E}$ representing that $p$ immediately justifies you in believing that $p$ iff $p$ is true.

Doxastic Conservatism: Your experience E representing that $p$ immediately justifies you in believing that $p$ if you believe that $p$.

Huemer's Phenomenal Conservatism: Your experience E representing that $p$ immediately justifies you in believing that $p$ if E makes it seem to you as if $p .^{14}$

The phenomenon of blindsight most obviously puts pressure on externalist conceptions of experiential justification such as Reliabilism and Truth-Externalism but it also undermines certain internalist conceptions such as Doxastic conservatism and Huemer's Phenomenal Conservatism. What is often overlooked is that examples such as the phenomenon of blindsight not only play a negative function in undermining certain approaches but can also have a positive function, motivating the close connection between epistemology and philosophy of mind and the significance of purely phenomenological analyses in particular. What this example indicates is that a descriptive, first-person analysis of experiences must be present at the very beginning of all epistemology. Epistemological theories must be preceded by phenomenological analyses. Accordingly, epistemology must not proceed "from above" by linking the justificatory force of experiences to external factors such as reliability. Types of justification (immediate vs inferential) and degrees of justification are linked to modes of givenness. What is given originally, and only what is given originally, can be immediately justified (Hua III/1, p. 326). Also, the clearer and more distinct the experience is, the more justification it provides (Hua XXIV, p. 347).

The phenomenological difference that S's experience represents and has originary givenness with respect to the circle in $\mathrm{R} 1$ and represents but lacks originary givenness with respect to the triangle in R2 correlates to the epistemological difference that $S$ is immediately justified in believing that there is a circle in $R 1$ but is not immediately justified in believing that there is a triangle in R2. The most straightforward explanation for this correlation is our phenomenological conception of experiential justification (PCEJ) introduced in Section 2. Experiences justify by virtue of their distinctive phenomenal character. Accordingly, if a perceptual experience $\mathrm{E}$ lacks its distinctive phenomenal character with respect to

14 For a more detailed analysis of Huemer's phenomenal conservatism and how it is undermined by the phenomenon of blindsight (cf. Berghofer 2018c). 
$p$, E cannot immediately justify believing that $p$. This is how experimental research concerning blindsight supports our phenomenological epistemology.

\section{Exemplifying the Relevance of Experimental Psychology 3: Perceptual Learning}

Examples of perceptual learning have become increasingly popular in current philosophy of mind. According to psychologist Eleanor Gibson, perceptual learning, broadly speaking, "refers to an increase in the ability to extract information from the environment, as a result of experience and practice with stimulation coming from it" (Gibson 1969, p. 3). ${ }^{15}$ Susanna Siegel discusses the hypothetical example in which a person that has never seen a pine tree before gets hired to cut down pine trees (cf. Siegel 2010, p. 100). After several weeks, one is able to identify pine trees on sight and distinguish them visually from other trees. As Siegel rightly points out, one's experiences of pine trees before and one's experiences of pine trees after perceptual learning have taken place differ phenomenologically, i. e., they differ in their phenomenal character (cf. Siegel 2010, p. 101). ${ }^{16}$ Kevin Connolly discusses the example of an expert birdwatcher who is looking at a wren. Connolly is in agreement with Siegel when he states that "the perception of an expert birdwatcher is phenomenally different from the perception of a layperson, even when viewed under the exact same background conditions" (Connolly 2014, p. 2). ${ }^{17}$ Perceptual

15 For more details on the characteristics of perceptual learning (cf. Conolly 2017).

16 It should be mentioned that while it is the dominant position that perceptual learning involves changes in the experiences' phenomenal character, there is no universal agreement on this. Jack Lyons, for instance, argues that when a herpetologist and a novice look at a copperhead, although "it looks like a copperhead" to the herpetologist and "only like a snake to" the novice, both, the herpetologist and the novice, "have identical visual experiences" (Lyons 2009, p. 104). In this spirit, one might argue that perceptual learning only leads to different judgments/beliefs but not to a difference in the experiences' phenomenology. Let me say two things. First, it is implausible to make a statement such as "It looks like A to person P1 and like B [whereby $\mathrm{A} \neq \mathrm{B}$ ] to person $\mathrm{P} 2$, but $\mathrm{P} 1$ and $\mathrm{P} 2$ have identical visual experiences (in the sense that $\mathrm{P} 1$ and $\mathrm{P} 2$ have phenomenologically indistinguishable experiences)." For a criticism of Lyons's portrayal (cf. Vaassen 2016, p. 139). Second, the example of vernier acuity that I will focus on at the end of this section does not concern high-level properties such as "being a copperhead" but low-level properties such as failure of alignment. In my example it is undeniable that the experiences before and after perceptual learning differ phenomenologically.

17 Of course, Siegel and Connolly differ in the lessons they draw from this phenomenological difference. While Siegel argues that cases of perceptual learning show that even high-level properties such as being a pine tree can be perceptual contents, Connolly attempts to explain the phenomenological difference in terms of a subject's "attentional pattern onto other low-level properties” (Connolly 2014, p. 1). 
learning is a philosophically significant phenomenon that has obvious implications for philosophy of mind as it tells us something about the nature of perception. For instance, "the fact that perceptual learning occurs means that the causes of perceptual states are not just the objects in our immediate environment, as it seems at first glance. Rather, given the reality of perceptual learning, there is a long causal history to our perceptions that involves prior perception" (Connolly 2017, Section 3). When the expert birdwatcher and an ordinary person are looking at a wren from the same distance and angle, they are acquainted with the same object, but their respective experiences differ significantly. Perceptual experiences do not only present objects, they also shape future experiences. As Goldstone and Byrge put it: "Perception can be learned. Experience shapes the way people see and hear" (Goldstone and Byrge 2015, p. 812).

Of course, the claim that the physical objects that are perceived are not the sole causes of perceptual states and that foregoing experiences shape the way we perceive is perfectly in line with Husserl's phenomenological analysis of perception. This is implied by Husserl's conception of horizontal intentionality and his distinction between empty and motivated possibilities (Husserl 1982, p. 337). What is more, Husserl explicitly states that "experience is not an opening through which a world, existing prior to all experience, shines into a room of consciousness; it is not a mere taking of something alien to consciousness into consciousness" (Husserl 1969, p. 232).

The study of perceptual learning also exemplifies the fruitfulness of interdisciplinary research since it "raises important issues about the ontology of sensory experience, the relationship between cognition and perception, and the possibility of a theory-neutral perceptual ground for science" (Goldstone and Byrge 2015, p. 812). There are a great number of philosophically significant psychological studies that address, e. g., the relationship between perceptual learning and concept learning, showing that perception not only influences concept learning but is also influenced by the concepts we have learned (cf. Goldstone et al. 2009). Research in experimental psychology reveals that the difference between how the expert and the novice perceive the world is also manifested in brain wave activity such that approximately 164 milliseconds after being presented to objects of expertise, enhanced electrical activity takes place - for instance, when a bird expert is confronted with a bird picture (cf. Tanaka and Curran 2001).

While it is beyond doubt that perceptual learning is a philosophically interesting phenomenon with crucial implications for philosophy of mind, it is only very recently that researchers have begun to investigate whether we can draw genuinely epistemological lessons from this (cf. Brogaard and Gatzia 2017; Chudnoff 2017; Siegel 2017; Vaassen 2016). Does perceptual learning tell us something about experiential justification? The main thesis of this section is that 
perceptual learning has epistemological implications and does indeed tell us something about experiential justification.

I am particularly concerned with the following phenomenon:

Thesis perceptual learning (TPL):

Due to experience, practice, or gaining new information, the phenomenal character of my perceptual experiences of object $O$ can change such that new characteristics $\mathrm{C}_{\mathrm{i}}$ of $\mathrm{O}$ can be perceived in a way that my experiences with the "new" phenomenal character can justify me immediately in believing that $\mathrm{O}$ has $\mathrm{C}_{\mathrm{i}}$.

Alternatively, we may say that the following scenario is possible: TPL*:

Confronted with a physical object $\mathrm{O}$, person $\mathrm{S}$ cannot see that $\mathrm{O}$ has the feature F. Due to experience, practice, or gaining new information, $S$ can manage to see that $\mathrm{O}$ has $\mathrm{F}$. Once $\mathrm{S}$ sees $\mathrm{F}, \mathrm{S}$ is immediately justified in believing that $\mathrm{O}$ has F.

It is controversial whether the examples of perceptual learning, we have discussed so far (pine tree, wren recognition), exemplify my TPL. While Siegel argues that cases of perceptual learning show that even high-level properties, such as being a pine tree or being a wren, can be perceptual contents, i. e., represented by experience, she is hesitant to draw the conclusion that in such cases one is immediately justified in believing that the tree is a pine tree (cf. Siegel 2017). However, in what follows I present a simple example, showing that TPL is highly plausible.

Vernier acuity ${ }^{18}$ :

Vernier acuity can be defined as "a measure of one's ability to detect failures of alignment between line segments” (Chudnoff 2017, p. 8). Vernier acuity is an experimentally well-studied phenomenon. McKee and Westheimer (1978)

18 Vernier acuity and its philosophical implications concerning perceptual learning and experiential justification are discussed in Chudnoff (2017). 
confronted test subjects with pictures like the one above, with the result that "every test subject showed some improvement in vernier acuity with practice" (McKee and Westheimer 1978, p. 259). More precisely, "[t]he overall decline in threshold after 2,000-2,500 responses is about 40\%" (McKee and Westheimer 1978, p. 259).

Assume person $\mathrm{S}$ is looking at the picture and is unable to spot any failure of alignment. S seems to see one straight line. After some practice, S looks again at the picture and sees that there is failure of alignment. $S$ is now immediately justified in believing that there is failure of alignment simply because she can see it. $\mathrm{S}$ seems to be visually aware of a failure of alignment. This scenario exemplifies TPL. Due to practice the phenomenal character of the experience changes such that it gains a presentive character concerning the failure of alignment. Once the experience has such a phenomenal character, the experience provides immediate justification for believing that there is a failure of alignment. Accordingly, this is another example that highlights how an experience's phenomenology determines an experience's justificatory force. Our phenomenological conception of experiential justification provides the most natural and straightforward account of such examples. The examples we discussed in this paper, namely optical illusion, blindsight, and perceptual learning, are not hypothetical thought experiments but are real-world examples well-studied in experimental psychology. The more empirical research can reveal about the nature of perception, the better for a phenomenological epistemology. This is particularly true for research that reveals something about how it is for persons to undergo certain experiences. This is because a phenomenological epistemology intrinsically links an experience's justificatory force to its phenomenal character. While the previous examples showed that empirical research can provide a significant input, the following section discusses some of the limits of empirical research.

\section{Concluding Remarks on the Limits of Empirical Research}

In the previous sections we have seen that although phenomenology and the empirical sciences employ very different methodologies, a mutually beneficial relationship is possible. Concerning phenomenology and experimental psychology, this is because both disciplines tackle similar topics from different perspectives using different methods. In the best case scenarios, phenomenological insights and experimental findings support and complement each other. We focused on epistemological issues and the question of how empirical findings can have a positive impact on phenomenological-epistemological investigations. Since a phenomenological epistemology closely connects epistemology and 
philosophy of mind, such a positive impact is to be expected. Sections 3-5 exemplified this positive impact.

However, in spite of all that, there are limits to the scope of empirical research. In current philosophy, naturalist approaches enjoy much popularity and even in phenomenology there are certain ambitions to naturalize phenomenology (cf., e. g., Petitot et al. 1999 and Zahavi 2010). While such projects of naturalizing phenomenology often succeed in illuminating significant and promising ways of connecting phenomenological and empirical research, for me there is no doubt that Husserlian phenomenology is genuinely anti-naturalistic. Concerning naturalism, we distinguish between ontological and methodological forms of naturalism.

Ontological Naturalism: Everything can be reduced to the physical, i. e., there are only physical objects.

Methodological Naturalism: Only the methods of the natural sciences are acceptable, which is why philosophy must be an empirical discipline.

There are a number of reasons why phenomenology is incompatible particularly with Methodological Naturalism. These reasons range from Husserl's ambition to establish phenomenology as the ultimate science that bestows legitimacy on all the individual sciences including mathematics and physics, to the fact that phenomenological insights are a priori eidetic insights about structures of consciousness and reality, to its descriptive, first-person character. Here I focus on this final aspect, the first-person character of phenomenology, since this connects well to the previous sections.

Husserl does not classify experiences according to the bodily organs that produce them. He does not link justificatory force to causality or other external factors such as reliability or truth. What counts for him is how acts present their contents, how objects are given within the respective acts. The focus is on the phenomenal character of the act, not on any external factor. If, following Husserl (cf. Husserl 1982, pp. 35f.), we understand naturalism as implying that for all areas of possible knowledge, including philosophy, only the methods of the natural sciences are valid forms of gaining insight, then Husserl's descriptive methodology is at odds with naturalism. This is because by the "methods of the natural science" we understand investigations from the third-person perspective, investigations that rely on and are limited to magnitudes that can be quantified, measured, and linked to external, causal influences. ${ }^{19}$ In this sense, investigating experiences in

19 It should be mentioned, however, that there are trends in current experimental psychology that explicitly argue for incorporating the first-person perspective to science, emphasizing the significance of Husserlian phenomenology. One such proposal is Liliana Albertazzi's "experimental phenomenology" (cf. Albertazzi 2013a, 2013b, 2019). 
the naturalist manner, from the third-person perspective, means, e. g., identifying and examining the relevant brain states that are linked to the respective (types of) experiences, and shedding light on the causal relationship between the external stimuli and one's bodily functions. It should be clear that such a methodology is clearly different from a phenomenological descriptive analysis of what it is like from the first-person perspective to undergo certain experiences.

In recent debates, philosophers such as Thomas Nagel have argued, in a somewhat Husserlian spirit, that the what-it-is-like aspect of consciousness is an essentially subjective character that is necessarily out of reach of the natural sciences (cf. Nagel 1974). ${ }^{20}$ Concerning the limits of physics, Nagel says:

Similarly, I believe that physics is only one form of understanding, appropriate to a broader but still limited subject matter. To insist on trying to explain the mind in terms of concepts and theories that have been devised exclusively to explain nonmental phenomena is, in view of the radically distinguishing characteristics of the mental, both intellectually backward and scientifically suicidal. (Nagel 1986, p. 52)

This is in perfect agreement with a phenomenological understanding of physics, according to which physics can only deliver a perspective on nature, not a purely objective picture that is independent of the physicist and her experiences. As Edith Stein puts it: "What physics [...] reveals pertains to the real nature but it never exhausts nature. And what evades the web of mathematical formulas is not less 'real' than what is captured by mathematics" (Stein 2004, p. 62). Here we find three motifs that are typical for a phenomenology of physics. First, phenomenology does not dispute the success of physics, neither does it object to the implementation of mathematics. Secondly, however, the mathematical picture delivered by physics only reveals one perspective of nature. Even if we manage to get a mathematical grip on nature, what we gain from this can never be an exhaustive picture of nature. "We have seen that the methods of the exact natural sciences do not capture reality in its totality, instead they are only concerned with certain sides of nature" (Stein 2004, p. 73). ${ }^{21}$ Thirdly, not being mathematizable does not imply not being real. This is not only true for certain aspects of nature but also for totally different entities including values, essences, and consciousness. Mathematics is

20 For similarities between Nagel and Husserl, cf. Ratcliffe 2002, Moran 2013, and Tieszen 2016, pp. 513f.

21 "Phenomenology is not out to dispute the value of science and is not denying that scientific investigations can lead to new insights and expand our understanding of reality. But phenomenologists do reject the idea that natural science can provide an exhaustive account of reality. Importantly, this does not entail that phenomenology is, as such, opposed to quantitative methods and studies. The latter are excellent, but only when addressing quantitative questions" (Zahavi 2018, p. 52). 
extremely useful in physics but this does not imply that any science (including philosophy, value theory, etc.) must attempt to mathematize its objects.

Indeed, one might side with Nagel since there is no indication of how the natural sciences could account for or replace the descriptive approach toward consciousness in elucidating what it means to undergo certain (types of) experiences. However, one might argue that the claim that the natural sciences will never be able to account for the subjective character of consciousness and experience is presumptuous and unjustified. Here the phenomenologist should reply that naturalism implies that a first-person approach can never succeed in grounding a scientific enterprise. Even if the natural sciences might one day account for the subjective character of experience, phenomenology is doing it right now in a descriptive manner. In this sense, the success of phenomenology in investigating experiences from the first-person perspective and in thereby grounding a scientific enterprise that is justified and informative undermines naturalism. The naturalist might, of course, deny the success of phenomenology. Such an objection can only be met by the phenomenologist by establishing and clarifying phenomenology as a scientific enterprise and by demonstrating its virtues.

Funding Statement: This work was supported by a grant of the Austrian Research Fund (FWF): P31758.

\section{References}

Albertazzi, L. (2019). "Experimental phenomenology: what it is and what it is not," Synthese. doi: 10.1007/s11229-019-02209-6.

Albertazzi, L. (ed.) (2013a). Handbook of Experimental Phenomenology (Malden: Wiley-Blackwell). Albertazzi, L. (2013b). ‘Experimental phenomenology: an introduction', in L. Albertazzi (ed.). Handbook of Experimental Phenomenology (Malden: Wiley-Blackell), pp. 1-36.

Antonelli, M. (1994). Die experimentelle Analyse des Bewußtseins bei Vittorio Benussi (Amsterdam: Rodopi).

Antonelli, M. (2018). Vittorio Benussi in the History of Psychology: New Ideas of a Century Ago (Cham: Springer).

Antonelli, M. and Manotta, M. (2009). "Meinongs und Benussis Phänomenologie der Wahrnehmung," Meinong Studies 3: 123-173.

Benussi, V. (1906/2002). ‘Experimentelles über Vorstellungsinadäquatheit', in M. Antonelli (ed.). Psychologische Schriften 1 (Amsterdam: Rodopi), pp. 155-228.

Benussi, V. (1904). 'Zur Psychologie des Gestalterfassens. (Die Müller-Lyersche Figur)', in A. Meinong (ed.). Untersuchungen zur Gegenstandstheorie und Psychologie (Leipzig: Barth), pp. 303-480.

Berghofer, P. (2018a). "Why Husserl's universal empiricism is a moderate rationalism," Axiomathes 28 (5), 539-563. 
Berghofer, P. (2018b). "Husserl's conception of experiential justification: what it is and why it matters," Husserl Studies 34 (2), 145-170.

Berghofer, P. (2018c). "Towards a phenomenological conception of experiential justification," Synthese. doi: 10.1007/s11229-018-1744-5.

Berghofer, P. (2019a). “On the nature and systematic role of evidence: Husserl as a proponent of mentalist evidentialism?” European Journal of Philosophy 27 (1), 98-117.

Berghofer, P. (2019b). “Husserl's noetics - towards a phenomenological epistemology," The Journal of the British Society for Phenomenology 50 (2), 120-138.

BonJour, L. (1998). In Defense of Pure Reason (Cambridge: Cambridge University Press).

Boring, E. (1929). A History of Experimental Psychology (New York: The Century Co).

Brogaard, B. and Gatzia, D. (2017). "The real epistemic significance of perceptual learning," Inquiry 61 (5-6), 543-558. doi: 10.1080/0020174X.2017.1368172.

Chudnoff, E. (2017). “The epistemic significance of perceptual learning," Inquiry 61 (5-6), 520542. doi: 10.1080/0020174X.2017.1357496.

Connolly, K. (2017). 'Perceptual learning’, The Stanford Encyclopedia of Philosophy (Summer 2017 Edition), Edward N. Zalta (ed.)., URL = https://plato.stanford.edu/archives/sum2017/ entries/perceptual-learning/ (accessed on 27th Nov. 2019).

Connolly, K. (2014). "Perceptual learning and the contents of perception," Erkenntnis 79 (6), 1407-1418. doi: 10.1007/s10670-014-9608-y.

Drummond, J. (2007). Historical Dictionary of Husserl's Philosophy (Lanham, MD: The Scarecrow Press).

Erhard, C. (2014). Denken über nichts - Intentionalität und Nicht-Existenz bei Husserl (Berlin: De Gruyter).

Ghijsen, H. (2016). The Puzzle of Perceptual Justification (Switzerland: Springer).

Gibson, E. (1969). Principles of Perceptual Learning and Development (New York: AppletonCentury-Crofts).

Goldstone, R. and Byrge, L. (2015). 'Perceptual learning,' in M. Matthen (ed.). Oxford Handbook of the Philosophy of Perception (Oxford: Oxford University Press), pp. 812-832.

Goldstone, R., Gerganov, A., Landy, D. and Roberts, M. (2009). 'Learning to see and conceive', in L. Tommasi, M. Peterson and L. Nadel (eds.). Cognitive Biology, (Cambridge: The MIT Press), pp. 163-188.

Heffernan, G. (2009). “On Husserl's remark that '[s]elbst eine sich als apodiktisch ausgebende Evidenz kann sich als Täuschung enthüllen...' (XVII 164:32-33): does the phenomenological method yield any epistemic infallibility?" Husserl Studies 25 (1): 15-43.

Hopp, W. (2011). Perception and Knowledge: A Phenomenological Account (Cambridge: Cambridge University Press).

Hopp, W. (2016a). 'Phenomenal conservatism and the principle of all principles', in D. Dahlstrom, A. Elpidorou and W. Hopp (eds.). Philosophy of Mind and Phenomenology (New York: Routledge), pp. 180-202.

Hopp, W. (2016b). 'Empty intentions and phenomenological character: a defense of inclusivism', in T. Breyer and C. Gutland (eds.). Phenomenology of Thinking (London: Routledge), pp. 44-61.

Hua III/1. (1976). Ideen zu einer reinen Phänomenologie und phänomenologischen Philosophie, Erstes Buch. K. Schuhmann (ed.).

Hua IX. (1968). Phänomenologische Psychologie, Vorlesungen Sommersemester 1925. W. Biemel (ed.). Hua XVI. (1973). Ding und Raum, Vorlesungen 1907. U. Claesges (ed.).

Hua XIX/1. (1984). Logische Untersuchungen, Zweiter Band, Erster Teil: Untersuchungen zur Phänomenologie und Theorie der Erkenntnis. U. Panzer (ed.). 
Hua XIX/2. (1984). Logische Untersuchungen, Zweiter Band, Zweiter Teil: Untersuchungen zur Phänomenologie und Theorie der Erkenntnis. U. Panzer (ed.).

Hua XX/1. (2002). Logische Untersuchungen, Ergänzungsband, Erster Teil: Entwürfe zur Umarbeitung der VI. Untersuchung und zur Vorrede für die Neuauflage der Logischen Untersuchungen (Sommer 1913). U. Melle (ed.).

Hua XXIV. (1984). Einleitung in die Logik und Erkenntnistheorie, Vorlesungen 1906/07. U. Melle (ed.). Hua XXV. (1987). Aufsätze und Vorträge (1911 - 1921). T. Nenon and H.R. Sepp (ed.).

Hua XXXVIII. (2004). Wahrnehmung und Aufmerksamkeit, Texte aus dem Nachlass (1893-1912). T. Vongher and R. Giuliani (ed.).

Huemer, M. (2001). Skepticism and the Veil of Perception (Lanham, MD: Rowman \& Littlefield Publishers).

Husserl, E. (2001). Logical Investigations, Vol. 2, trans. J.N. Findlay (London: Routledge). Husserl, E. (1982). Ideas Pertaining to a Pure Phenomenology and to a Phenomenological Philosophy, First Book, trans. F. Kersten (The Hague: Martinus Nijhoff).

Husserl, E. (1969). Formal and Transcendental Logic, trans. D. Cairns (The Hague: Martinus Nijhoff).

Lau, H. (2008). 'Are we studying consciousness yet?', in L. Weiskrantz and M. Davies (eds.). Frontiers of Consciousness (Oxford: Oxford University), pp. 245-258.

Lyons, J. (2009). Perception and Basic Beliefs (Oxford: Oxford University Press).

Madary, M. (2017). Visual Phenomenology (Cambridge: The MIT Press).

McKee, S. and Westheimer, G. (1978). "Improvement in Vernier acuity with practice," Perception \& Psychophysics 24 (3): 258-262.

Meinong, A. (1888), Über den Begriff und Eigenschaften der Empfindungen, in Meinong Gesamtausgabe I, Roderick Chisholm, Rudolf Haller and Rudolf Kindinger (eds.) (Graz), pp. 109-185.

Meinong, A. (1906), Über die Erfahrungsgrundlagen unseres Wissens, in Meinong Gesamtausgabe $V$, Roderick Chisholm, Rudolf Haller and Rudolf Kindinger (eds.) (Graz), pp. 367-481.

Moran, D. (2013). “'Let’s look at it objectively’: why phenomenology cannot be naturalized," Royal Institute of Philosophy Supplement 72: 89-115.

Nagel, T. (1974). “What is it like to be a bat?,” The Philosophical Review 83 (4): 435-450.

Nagel, T. (1986). The View from Nowhere (Oxford: Oxford University Press).

Petitot, J., Varela, F., Pachoud, B. and Roy, J.M. (eds.). (1999). Naturalizing Phenomenology (Stanford: Stanford University Press).

Ratcliffe, M. (2002). "Husserl and Nagel on subjectivity and the limits of physical objectivity," Continental Philosophy Review 35 (4): 353-377.

Siegel, S. (2017). The Rationality of Perception (Oxford: Oxford University Press).

Siegel, S. (2010). The Contents of Visual Experience (Oxford: Oxford University Press).

Smithies, D. (2014). 'The phenomenal basis of epistemic justification', in M. Sprevak and J. Kallestrup (eds.). New Waves in Philosophy of Mind (New York: Palgrave Macmillan), pp. 98-124.

Sobrak-Seaton, M. (2018). 'Edith Stein', in A. Staiti and E. Clarke (eds.). The Sources of Husserl's 'Ideas I’, (Berlin: De Gruyter), pp. 299-300.

Soffer, G. (1991). Husserl and the Question of Relativism, (Dordrecht: Kluwer).

Stein, E. (2004). Einführung in die Philosophie, Edith Stein Gesamtausgabe Band 8 (Freiburg: Herder).

Stein, E. and Husserl, E. (2018). 'Critique of Theodor Elsenhans and August Messer (1917) (Edith Stein's Draft,' trans. E. Clarke, in A. Staiti and E. Clarke (eds.). The Sources of Husserl's 'Ideas I’ (Berlin: De Gruyter), pp. 449-468. 
Tanaka, J. and Curran, T. (2001). "A neural basis for expert object recognition," Psychological Science 12 (1): 43-47.

Tieszen, R. (2016). "Eidetic results in transcendental phenomenology: against naturalization," Phenomenology and the Cognitive Sciences 15 (4): 489-515.

Tucker, C. (2010). “Why open-minded people should endorse dogmatism," Philosophical Perspectives 24 (1): 529-545.

Tucker, C. (2013). 'Seemings and justification: an introduction', in C. Tucker (ed.). Seemings and Justification. New Essays on Dogmatism and Phenomenal Conservatism (New York: Oxford University Press), pp. 1-29.

Tye, M. (2015). 'Qualia', The Stanford Encyclopedia of Philosophy (Fall 2015 Edition), in Edward N. Zalta (ed.)., URL = http://plato.stanford.edu/archives/fall2015/entries/qualia/ (accessed on 27th Nov. 2019).

Vaassen, B. (2016). "Basic beliefs and the perceptual learning problem: a substantial challenge for moderate foundationalism,” Episteme 13 (1): 133-149.

Weiskrantz, L. (1998). Blindsight: A Case Study and Implications (Oxford: Oxford University Press).

Zahavi, D. (2010). 'Naturalized phenomenology', in S. Gallagher and D. Schmicking (eds.). Handbook of Phenomenology and Cognitive Science (Dordrecht: Springer), pp. 3-19.

Zahavi, D. (2018). Phenomenology: The Basics (London: Routledge). 